\title{
Ethical planning for an influenza pandemic
}

\author{
HL Barr, JT Macfarlane, O Macgregor, R Foxwell, V Buswell and WS Lim
}

\begin{abstract}
A UK Pandemic Influenza Contingency Plan was developed in 2006 but little research has since been carried out as to how ethically acceptable it will be to society. A survey containing two hypothetical scenarios was distributed to 1,018 hospital staff. The survey considered their attitudes to the professional and ethical responsibilities of healthcare workers, and to resource allocation on the intensive care unit (ICU). Of those distributed, $406(40 \%)$ surveys were returned. During a pandemic, $320(79 \%)$ healthcare professionals would continue to work and $339(83 \%)$ felt it would be unprofessional for doctors to leave work. Only 218 (54\%) chose the same patient for the last ICU bed. Most staff surveyed felt they should (professionally) and would (voluntarily) work during a pandemic despite high personal risk. A wide diversity of opinion existed regarding resource allocation of ICU beds. These ethical issues require open debate to ensure UK pandemic plans are ethically acceptable and practically applicable.
\end{abstract}

KEY WORDS: ethics, influenza, pandemic, ration, resource, triage

\section{Introduction}

There is widespread international concern that the world is closer to an influenza pandemic than it has been for almost 40 years. ${ }^{1}$ In the UK, the Department of Health published guidelines for planning for an influenza pandemic. ${ }^{2}$ There is little research, however, into how ethically acceptable, and therefore practically applicable, these plans will be to acute hospital trusts planning delivery of healthcare. A survey of healthcare workers (HCWs) was conducted to determine attitudes towards duty of care and resource allocation dilemmas that may arise during a pandemic.

\section{Methods}

A survey was developed containing two hypothetical scenarios that could arise during a pandemic. The first scenario addressed some aspects of the professional and ethical responsibilities of HCWs (Box 1). The second scenario considered the problem of resource allocation and which patient should use the last intensive care unit (ICU) bed (Box 2).
The survey was distributed to $1,018 \mathrm{HCW}$ at Nottingham University Hospitals NHS Trust, City Hospital Campus, (a large 1,200-bed teaching hospital). The survey included all 468 doctors identified via the hospital switchboard, 53 medical students surveyed during a lecture and 500 wardbased nurses and support workers. The replies were anonymous except for information regarding age, occupation, gender and whether they had children at home. Results were analysed using the Chi square

Box 1. Scenario one and corresponding questions.

- The UK is in the middle of an overwhelming influenza pandemic

- There has been severe morbidity and mortality among staff at a nearby hospital indicating the influenza virus is unusually transmissible and virulent

- Locally, antiviral therapy has run out

- A group of younger doctors, nurses and nonmedical support staff (group A) are worried that they are putting both themselves and their young families at risk. They are seeking to go home and stay off work

- The rest of the staff (group B) feels it is unfair to ask group A to stay to provide care. They agree among themselves that they will stay and try to manage on their own, despite high personal risk and overstretched resources

- The hospital managers are told about this and demand that everyone who is available to work must turn up or face disciplinary action

Q1. Is it professionally right for members of the following groups to go home and leave their colleagues to cope?
a. Doctors?
b. Nurses?
c. Non-medical support staff?

Q2. Is it ethically right for members of the following groups to go home and leave their colleagues to cope?
a. Doctors?
b. Nurses?
c. Non-medical support staff?

Q3. Would you join: group A (go home) or group B (stay at work)?

Q4. Should there be a legal framework to force NHS staff to work during a pandemic?

\section{HL Barr}

BMedSci BMBS MRCP, Specialist Registrar in Respiratory

Medicine

\section{JT Macfarlane} DM FRCP MRCGP, Consultant Respiratory Physician

O Macgregor RGN, Matron for Acute Medicine and Specialties

R Foxwell BMedSci BMBS, Specialist Training Year 1 General Practitioner Trainee

V Buswell BMedSci, Medical Student

WS Lim DM FRCP, Consultant Respiratory Physician

Nottingham University Hospitals NHS Trust, City Hospital Campus 


\section{Box 2. Scenario two and corresponding questions.}

\section{Patient A}

A 25-year-old previously fit and well university student with severe primary viral pneumonia has deteriorated and is critically ill with respiratory, renal and cardiac failure. $\mathrm{He}$ has a $20 \%$ chance of survival, even with ventilation and critical care. On the intensive care unit (ICU) he would require a high input of resources (eg intensive nursing, dialysis etc)

\section{Patient B}

A 67-year-old man with a flu exacerbation of his moderately severe chronic obstructive pulmonary disease (COPD) has deteriorated in spite of non-invasive ventilation and requires mechanical ventilation if he is to survive. He is judged to have about a $70 \%$ chance of survival, if he is ventilated on ICU. As a result of his COPD, his long-term life expectancy is approximately three years

\section{Patient C}

A 51-year-old patient (a non-EU foreign national) has come to the UK for elective private treatment. He has developed severe postoperative pneumonia following a successful coronary artery bypass graft operation. He has a $60 \%$ chance of survival with ventilation and critical care input. Should he survive, his long-term outlook is good

Q5. Given a choice of A or B only, who do you think should get the last ICU bed?

Q6. Given a choice of A, B and C, who do you think should get the last ICU bed?

statistical test and a p value of $<0.05$ was considered statistically significant.

\section{Results}

Of 1,018 surveys distributed, 406 (40\%) were returned. Table 1 summarises respondent characteristics.

\section{Responses to scenario one}

Scenario one addressed the issue of duty of care among healthcare workers and is given in full in Box 1. The results concerning scenario one are summarised in Table 2. Regarding personal actions during a pandemic, 76 (19\%) HCWs said they would leave work, $320(79 \%)$ said they would stay at work and $10(2 \%)$ were unsure or did not answer. Significantly more nurses than doctors would choose to go home (31 (23\%) of 134 nurses $v 26$ (14\%) of 184 doctors; $\mathrm{p}=0.03$ ), as would staff with children at home compared with staff without children (39 (25\%) of $157 v 36$ $(15 \%)$ of $249 ; \mathrm{p}=0.01)$. Gender and age did not significantly affect opinion.

Regarding action by others, significantly more male respondents than females felt it was professionally acceptable for doctors, nurses and non-medical support workers to go home (for doctors $31(20 \%)$ of 158 males $v 26(10 \%)$ of 248 females, $\mathrm{p}=0.01$; for nurses $32(20 \%)$ of 158 males $v 25(10 \%)$ of 248 females, $\mathrm{p}=0.01$; for non-medical support workers 57 (36\%) of 158 males $v 65(26 \%)$ of 248 females, $\mathrm{p}=0.03)$. Occupation, age and having children at home did not significantly affect results.

Regarding a legal framework for NHS workers during a pandemic, $332(82 \%)$ staff did not feel there should be legal powers to force them to stay at work, 69 (17\%) felt there should be, and five $(1 \%)$ did not answer or were unsure. Occupation, age, gender and having children at home did not significantly affect results.

\section{Responses to scenario two}

Scenario two addressed the issue of resource allocation (see Box 2). When staff were asked to choose between patient A or B when allocating the last ICU bed, $325(80 \%)$ choose patient A, 78 (19\%) chose patient B, two choose neither and one was undecided $(<1 \%)$. When then given the choice of three patients 404 (99\%) responded: 218 (54\%) chose patient A; 49 (12\%) chose patient B; and 137 (34\%) chose patient C. Occupation affected patient choice with significantly more doctors than nurses picking patient A. Of the 182 doctors who responded, $109(60 \%)$ choose patient A, $9(5 \%)$ choose patient B and $64(35 \%)$ choose patient C. Of 134 nurses who responded, $63(47 \%)$ choose patient A, 28 (21\%) choose patient B and $43(32 \%)$ choose patient $\mathrm{C} ; \mathrm{p}<0.01$. Those with children at home were more likely to pick patient B than those without $(27$ (17\%) $v 22(9 \%) ; \mathrm{p}=0.01)$.

\section{Discussion}

The most important finding was the wide range of opinion prevalent among HCWs at a large acute trust in relation to healthcare delivery during a pandemic.

\section{Duty of care}

During an influenza pandemic, a fifth of HCWs indicated they would not be willing to work when there was a high risk of infection and limited personal protection. This proportion rose to a quarter in staff with children at home. This level of absenteeism, compounded by $15 \%$ of staff projected to be off sick, ${ }^{2}$ may reduce the workforce by over a third and would greatly impact on the ability of the NHS to provide healthcare to patients.

Since the 19th century physicians have had an ethical obligation to care for the sick in an epidemic. ${ }^{3}$ According to guidance from the General Medical Council, 'you must not refuse to treat a patient because you may be putting yourself at risk...you should take reasonable steps to protect yourself'. ${ }^{4}$ Conversely, in response to the threat of nuclear attack in 1988, the British Medical Association stated:

Professional concern for the injured should be tempered with reason, and doctors or nurses should not consider it a duty to risk their lives. ${ }^{5}$

In accordance with this, the majority of survey respondents did not feel they should be forced by law to work. The lack of 
Table 1. Characteristics of the 406 respondents.

\begin{tabular}{lc}
\hline Characteristic & Number (\%) \\
\hline Mean age (years) & 34.7 \\
Under 26 & $126(31)$ \\
$27-37$ & $134(33)$ \\
$38+$ & $140(35)$ \\
Not completed & $6(1)$ \\
Number of males & $158(39)$ \\
Children at home & $157(39)$ \\
Occupation & \\
Medical & $237(58)$ \\
$\quad$ Consultant & $74(18)$ \\
Staff grade/registrar & $44(11)$ \\
F2/SHO & $39(10)$ \\
F1 & $27(6)$ \\
Student & $53(13$ \\
Nursing staff & $145(36)$ \\
$\quad$ Qualified & $134(33)$ \\
Student & $11(3)$ \\
Physiotherapist & $7(2)$ \\
Non-medical support staff & $17(4)$ \\
\hline
\end{tabular}

$\mathrm{F}=$ foundation year; $\mathrm{SHO}=$ senior house office

clear ethical guidance for the duty of care for HCWs during a pandemic in the UK guidelines is mirrored in the medical codes of ethics of other countries. ${ }^{6}$

The extent to which HCWs are obliged to risk their lives to deliver clinical care is difficult to quantify, and this scenario study can only highlight the potential reactions from individuals faced by a real pandemic. Healthcare workers are unique in their ability to provide care and it can be argued that this increases their professional obligation to provide it. ${ }^{7}$ Applying the principle of reciprocity, if society affirms that HCWs should work despite high personal risk, society in turn has a responsibility to support and protect them. This would comprise of adequate personal protection equipment and may embrace priority of vaccination, provision of antiviral prophylaxis, plus psychological, practical and emotional support for HCWs and family members.

\section{Resource allocation}

This survey demonstrated a wide diversity of opinion regarding resource allocation of critical care beds during a pandemic, with occupation and having children at home significantly affecting patient choice.

Difficult decisions about allocation of ICU beds occur on a daily basis. Doctors acknowledge that external pressures and time constraints can contribute to the admission of inappropriate patients. ${ }^{8}$ During a pandemic there will be immense strain on overstretched resources, particularly in the intensive care setting. Conflicts may occur if HCWs, patients and relatives hold differing views and policies have not been agreed $a$ priori at a public level. As occurred with severe acute respiratory syn-
Table 2. Number of responses to the question, 'Is it professionally and ethically right for members of the following groups to go home and leave their colleagues to cope at work?'.

\begin{tabular}{lll}
\hline Group & $\begin{array}{l}\text { Professionally right to go } \\
\text { home (n/total number of } \\
\text { of responses to } \\
\text { question (\%)) }\end{array}$ & $\begin{array}{l}\text { Ethically right to go } \\
\text { home (n/total number } \\
\text { of responses to } \\
\text { question (\%)) }\end{array}$ \\
\hline $\begin{array}{l}\text { Doctor } \\
\text { Nurse }\end{array}$ & $57 / 396(14)$ & $87 / 397(22)$ \\
Non-medical \\
support staff & $123 / 3900(14)$ & $90 / 397(23)$ \\
\hline
\end{tabular}

$\mathrm{n}=$ number.

drome, HCWs themselves are liable to become patients in their own hospital, intensifying the ethical complexities relating to decision making.

Several contrasting techniques may be considered to rationalise care in a pandemic setting, such as a quality-adjusted life-year's technique which gives priority to younger individuals, or triage techniques, based on an utilitarian approach which delivers the greatest medical benefit to the greatest number of people. , 10,11 During different phases of a pandemic such techniques will need to change or adapt, but a robust decisionmaking process used for resource rationing will be important. Ideally, this process would be developed in advance in a systematic, reproducible, transparent, flexible and fair way, and would involve public participation. The knowledge gained by advanced public involvement in the ethical basis and practical consequences of resource allocation during a pandemic can be used to address hurdles that need to be overcome in establishing ethical policy, consequently increasing public cooperation and acceptance of rationing decisions when a pandemic occurs.

\section{Limitations}

This study included the use of theoretical scenarios, which were developed with input from members of the Pandemic Influenza Clinical Management Guidelines Committee and were discussed by a local ethics of clinical practice committee. They therefore represent realistic projected scenarios. The answers given by respondents, however, cannot accurately predict the future decisions made by an individual in a pandemic setting.

Regarding resource allocation, the vast majority of staff followed the instructions to allocate the last ICU bed to one of the patients. Alternative answers, however, including 'unsure' and 'none of these patients' were given. If a lottery or random allocation option was offered more staff may have opted out of making evaluations of one patient against another and substituted chance instead.

The response rate of $40 \%$ was less than predicted. Nevertheless, this represents over 400 responses and to the authors' knowledge, is the first large attempt at examining the attitudes 
of HCWs to realistic scenarios in a pandemic setting. It is also unlikely that the opinion of the non-respondents would detract from the main message of this study - that there is a wide range of opinion among HCWs and real concern regarding the tension between duty of care and personal risk.

This survey targeted a highly specific subset of the population, mainly medical and nursing staff at one hospital campus. Further investigation is necessary to determine the attitudes of other HCWs in hospitals, and the community, and the general public as a whole. Other important ethical considerations in pandemic planning including civil liberty, privacy, research ethics and global governance implications were not addressed.

\section{Conclusions}

Complex ethical issues will arise multiple times during a pandemic. They therefore deserve attention as an integral part of planning for an influenza pandemic. We propose an ethical debate at a societal level, to establish clearer guidance on the duty of care of HCWs and resource allocation in a pandemic setting.

\section{Acknowledgements}

We are grateful to Professor John Saunders for reviewing the article and for his comments. We would also like to thank members of the Pandemic Influenza Clinical Management Guidelines Committee who contributed to the development of the clinical scenarios.

\section{References}

1 World Health Organization. Strategic action plan for pandemic influenza. Geneva: WHO, 2006. www.who.int/csr/resources/publications/influenza/WHO_CDS_EPR_GIP_2006_2/en/index.html

2 Department of Health. Pandemic influenza guidelines. London: DH, 2007. www.dh.gov.uk/en/pandemicflu/index.htm

3 Zuger A, Miles SH. Physicians, AIDS, and occupational risk: historic traditions and ethical obligations. JAMA 1987;258:1924-8 .

4 General Medical Council. Good medical practice. London: GMC, 2006. www.gmc-uk.org/guidance/good_medical_practice

5 British Medical Association. Nuclear attack: ethics and casualty selection. London: BMA, 1988.

6 University of Toronto Joint Centre for Bioethics Pandemic Influenza Working Group. Stand on guard for thee: ethical considerations in preparedness planning for pandemic influenza. Toronto: University of Toronto Joint Centre for Bioethics, 2005. www.utoronto.ca/jcb/home/documents/pandemic.pdf

7 Clarke CC. In harm's way. AMA physicians and the duty to treat. J Med Philos 2005;30:65-87.

8 Giannini A, Consonni D. Physicians' perceptions and attitudes regarding inappropriate admissions and resource allocation in the intensive care setting. Br J Anaesth 2006;96:57-62.

9 Torrance GW, Feeny D. Utilities and quality adjusted life years. Int J Technol Assess Health Care 1989;5:559-75.

10 Hick JL, O'Laughlin DT. Concept of operations for triage of mechanical ventilation in an epidemic. Acad Emerg Med 2006;13:223-9.

11 Christian MD, Hawryluck L, Wax RS et al. Development of a triage protocol for critical care during an influenza pandemic. CMAJ 2006; $175: 1377-81$. 